Article

\title{
In Silico Drug Repurposing Approach: Investigation of Mycobacterium tuberculosis FadD32 Targeted by FDA-Approved Drugs
}

\author{
Nolwazi Thobeka Portia Ngidi, Kgothatso Eugene Machaba and Ndumiso Nhlakanipho Mhlongo *
}

Citation: Ngidi, N.T.P.; Machaba, K.E.; Mhlongo, N.N. In Silico Drug Repurposing Approach: Investigation of Mycobacterium tuberculosis FadD32 Targeted by FDA-Approved Drugs. Molecules 2022, 27, 668. https://doi.org/ $10.3390 /$ molecules 27030668

Academic Editor: Stanislav Gobec

Received: 10 November 2021

Accepted: 9 January 2022

Published: 20 January 2022

Publisher's Note: MDPI stays neutral with regard to jurisdictional claims in published maps and institutional affiliations.

Copyright: (C) 2022 by the authors. Licensee MDPI, Basel, Switzerland. This article is an open access article distributed under the terms and conditions of the Creative Commons Attribution (CC BY) license (https:// creativecommons.org/licenses/by/ $4.0 /)$.
School of Laboratory Medicine and Medical Sciences, University of KwaZulu-Natal, Durban 4001, South Africa; 215022865@stu.ukzn.ac.za (N.T.P.N.); machabak@ukzn.ac.za (K.E.M.)

* Correspondence: mhlongon4@ukzn.ac.za; Tel.: +27-(0)3-1260-2428; Fax: +27-(0)3-1260-7792

\begin{abstract}
Background: Despite the enormous efforts made towards combating tuberculosis (TB), the disease remains a major global threat. Hence, new drugs with novel mechanisms against TB are urgently needed. Fatty acid degradation protein D32 (FadD32) has been identified as a promising drug target against TB, the protein is required for the biosynthesis of mycolic acids, hence, essential for the growth and multiplication of the mycobacterium. However, the FadD32 mechanism upon the binding of FDA-approved drugs is not well established. Herein, we applied virtual screening (VS), molecular docking, and molecular dynamic (MD) simulation to identify potential FDA-approved drugs against FadD32. Methodology/Results: VS technique was found promising to identify four FDA-approved drugs (accolate, sorafenib, mefloquine, and loperamide) with higher molecular docking scores, ranging from -8.0 to $-10.0 \mathrm{kcal} / \mathrm{mol}$. Post-MD analysis showed that the accolate hit displayed the highest total binding energy of $-45.13 \mathrm{kcal} / \mathrm{mol}$. Results also showed that the accolate hit formed more interactions with FadD32 active site residues and all active site residues displayed an increase in total binding contribution. RMSD, RMSF, Rg, and DCCM analysis further supported that the presence of accolate exhibited more structural stability, lower bimolecular flexibility, and more compactness into the FadD32 protein. Conclusions: Our study revealed accolate as the best potential drug against FadD32, hence a prospective anti-TB drug in TB therapy. In addition, we believe that the approach presented in the current study will serve as a cornerstone to identifying new potential inhibitors against a wide range of biological targets.
\end{abstract}

Keywords: Mtb-FadD32; drug repurposing; MD simulations; post-MD analysis

\section{Introduction}

Tuberculosis (TB) is an ancient infectious disease caused by the pathogenic bacillus Mycobacterium tuberculosis $(M t b)$; this disease is a major global health problem and is one of the top 10 causes of death worldwide [1]. The 2019 global statistics of TB reported, approximately 10 million people developed TB and approximately 1.4 million TB deaths occurred [1]. Currently, the approved first-line drugs for the treatment of TB are isoniazid (INH), rifampicin (RIF), pyrazinamide (PZA), and ethambutol (EMB) for a period of 6 to 9 months [2]. However, there is frequent emergence of strains that are resistant to these drugs, these strains include: multi-drug-resistant (MDR), extensively-drug-resistant (XDR), and total-drug-resistant (TDR) strains [3,4].

Drug-resistant TB is hindering progress towards combating TB and half a million people developed rifampicin-resistant TB and 78\% had MDR TB in 2019 [1]. The sudden emergence of the COVID-19 pandemic has caused the situation to worsen, consequently, reversing the progress made towards reducing the burden of TB [1]. In recognition of the enormous health, economic and social impacts posed by this disease on the public, research breakthroughs are needed to rapidly reduce TB cases [5]. Therefore, there is a demand for 
further research into the discovery of new drug targets, and new potent inhibitors with novel mechanisms of action against TB [6].

Mycolic acid is a major component of the bacterial cell wall, the thick waxy coat trait renders protection to the bacteria, hence, providing immunity against the host's immune system and current antibiotics $[7,8]$. The mycolic acid biosynthesis pathway is well-validated and used to identify potential targets for antimycobacterial drug development [9]. Fatty acid degradation protein D32 (FadD32) is required for the biosynthesis of mycolic acids, hence, essential for the growth and multiplication of the mycobacterium [10]. FadD32 is a bifunctional enzyme, it initially catalyzes meromycolic acid and ATP to form meromycoloyl-AMP, and then catalyzes the acyl chain transfer from meromycoloyl-AMP to the phosphopantetheinyl arm of the N-terminal ACP domain of Pks13 [10].

FadD32 (Figure 1) has been identified and proposed as a novel drug target for the development of potential drugs against TB $[10,11]$. The structure comprises two distinct domains, the N-terminal domain (1-483 residues) and the C-terminal domain (484-630 residues) [10]. FDA-approved drugs against FadD32 remain a mystery in literature. Hence, the FadD32 mechanism is not well established. Therefore, unknown FDA-approved drug against FadD32 has motivated the search for new potent FDA-approved drugs (drug repurposing) against FadD32, a novel potential target.

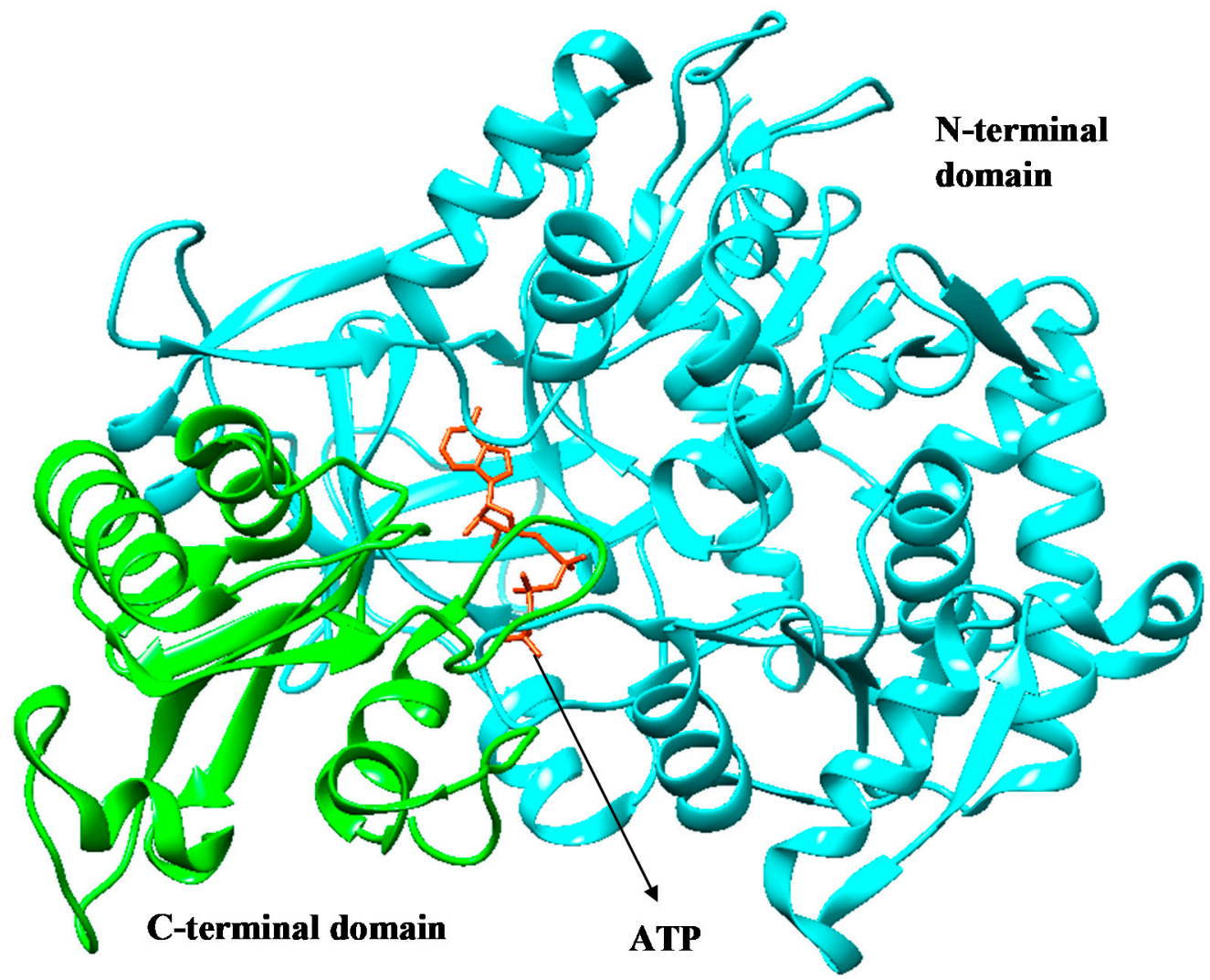

Figure 1. Three-dimensional (3D) structure of FadD32, showing the C-terminal domain (green) and the N-terminal domain (cyan), with the natural substrate, ATP (orange) [10].

Repurposing FDA-approved drugs is an effective, time-saving, and less expensive strategy to discover new molecules against drug targets of interest [12]. Hence, it is uncomplicated to develop the drugs since essential data about them is already available, which minimizes the risk of failure [13]. Repurposed drugs used in TB treatment include moxifloxacin, linezolid, clofazimine, amikacin, and meropenem [14,15], these drugs have proven to be effective against MDR-TB and XDR-TB $[15,16]$. Inhibitors that have the potential to target multiple drug targets/sites within the mycobacterial cell are imperative. To achieve the above, different computational methods can be applied [17]. 
Virtual screening (VS) has proven to be a powerful and indispensable tool in discovering small molecular inhibitors which bind to drug targets of interest [18]. The computeraided technique screens large libraries of compounds, filters, and discards undesirable compounds, hit compounds are identified and selected as lead compounds [19]. This work focuses on structure-based VS, a robust and useful technique that predicts the best interaction between ligands and target and ranks the ligands according to their affinity for the target site [20].

Another crucial computational method in this study is molecular dynamics (MD). MD is a computational simulations technique employed in the study of biological molecules to analyze the physical behavior of the constituent atoms and molecules [21]. MD simulations serve as an invaluable tool that gives insight into the structural changes of the protein at different time scales [22]. The receptor, ligand, and overall complex motions, which are vital information provided by MD simulations can be exploited for drug design processes [22].

The main goal of the present work is to apply the drug repurposing approach and to identify potential inhibitors against FadD32. This approach is focused on virtual screening (VS), molecular dynamics (MD), simulations and post-MD calculations. In addition, the study provides a molecular understanding of the surrogate structure (FadD32) and how it interacts with a ligand from a computational standpoint. Hence, the current study applied VS approach and identify four potential (Figure 2) FDA-approved hits (accolate, sorafenib, mefloquine, and loperamide).<smiles>COc1cc(C(=O)NS(=O)(=O)c2ccccc2C)ccc1Cc1cn(C)c2ccc(NC(=O)OC3CCCC3)cc12</smiles>

A<smiles>OC(c1cc(C(F)(F)F)nc2c(C(F)(F)F)cccc12)C1CCCCN1</smiles>

C

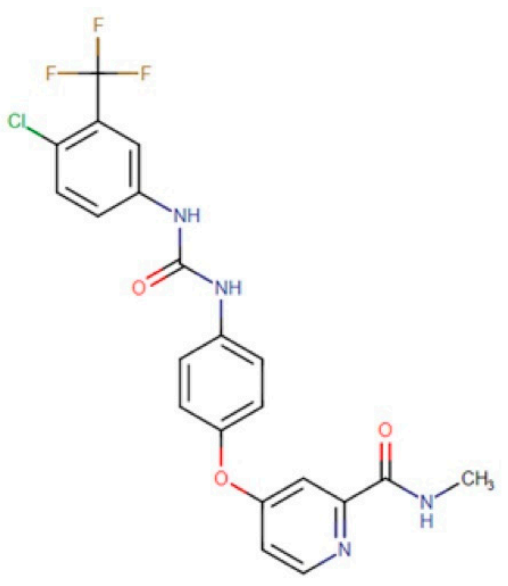

B

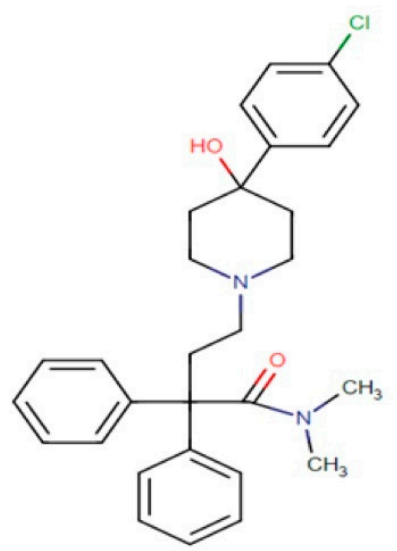

D

Figure 2. Chemical structures of accolate (A), sorafenib (B), mefloquine (C), and loperamide (D).

We believe the approach 'drug repurposing' could be carried out in the procedure of drug discovery of potential drugs against a wide range of biological targets. To the best of 
our knowledge, this is the first time where computational tools have been applied to reveal the impact of FadD32 upon the binding of FDA-approved drugs.

\section{Results and Discussion}

\subsection{Molecular Docking and Binding Free Energy}

All four hits (accolate, sorafenib, loperamide, and mefloquine) were subjected to docking followed by MMPBSA calculation to determine the accuracy of the ligand-receptor binding affinities. As shown in Table 1, the docking scores for all four drugs ranged from -8.0 to $-10.0 \mathrm{kcal} / \mathrm{mol}$.

Table 1. Binding free energy $(\mathrm{kcal} / \mathrm{mol})$ and the components of binding free energy of the different molecules.

\begin{tabular}{|c|c|c|c|c|c|c|}
\hline FDA-Approved Drugs & $\begin{array}{l}\text { Docking Score } \\
\text { (kcal/mol) }\end{array}$ & $\begin{array}{c}\Delta \mathrm{G}_{\text {bind }} \\
(\mathrm{kcal} / \mathrm{mol})\end{array}$ & $\begin{array}{c}\Delta \mathrm{E}_{\mathrm{vdw}} \\
(\mathrm{kcal} / \mathrm{mol})\end{array}$ & $\begin{array}{c}\Delta \mathrm{E}_{\text {ele }} \\
(\mathrm{kcal} / \mathrm{mol})\end{array}$ & $\begin{array}{c}\Delta \mathrm{G}_{\mathrm{gas}} \\
\text { (kcal/mol) }\end{array}$ & $\begin{array}{c}\Delta \mathrm{G}_{\text {sol }} \\
\text { (kcal/mol) }\end{array}$ \\
\hline Accolate & -9.3 & $-45.13 \pm 6.64$ & $-64.54 \pm 4.08$ & $-28.89 \pm 9.70$ & $-93.44 \pm 12.41$ & $48.31 \pm 6.95$ \\
\hline Sorafenib & -10.0 & $-32.73 \pm 3.87$ & $-51.64 \pm 2.92$ & $-27.74 \pm 8.37$ & $-73.37 \pm 8.36$ & $46.65 \pm 7.83$ \\
\hline Mefloquine & -8.0 & $-26.84 \pm 2.63$ & $-34.55 \pm 2.74$ & $-23.59 \pm 6.18$ & $-58.13 \pm 6.15$ & $31.29 \pm 4.97$ \\
\hline Loperamide & -8.5 & $-21.52 \pm 7.40$ & $-33.45 \pm 7.95$ & $-11.37 \pm 7.48$ & $-59.84 \pm 10.21$ & $28.39 \pm 6.01$ \\
\hline
\end{tabular}

To gain insight into the binding free energy profiles, the MM-PBSA approach [23] was also carried out for all systems. The total binding energies of all the systems ranged from -45.13 to $-21.52 \mathrm{kcal} / \mathrm{mol}$, with accolate $(-45.13 \mathrm{kcal} / \mathrm{mol})$ and sorafenib $(-32.73 \mathrm{kcal} / \mathrm{mol})$ showing the highest total binding energy while mefloquine $(-26.84 \mathrm{kcal} / \mathrm{mol})$ and loperamide $(-21.52 \mathrm{kcal} / \mathrm{mol})$ showing the lowest total binding energy (Table 1$)$. It was also observed that accolate also had the highest van der Waals and electrostatic contributions towards the total binding free energy $\left(\Delta \mathrm{E}_{\mathrm{vdw}}\right.$ of $-64.54 \mathrm{kcal} / \mathrm{mol}$ and $\Delta \mathrm{E}_{\mathrm{ele}}$ of $-28.89 \mathrm{kcal} / \mathrm{mol})$ and loperamide showed the lowest contributions $\left(\Delta \mathrm{E}_{\mathrm{vdw}}\right.$ of $-33.45 \mathrm{kcal} / \mathrm{mol}$ and $\Delta \mathrm{E}_{\text {ele }}$ of $-11.37 \mathrm{kcal} / \mathrm{mol}$ ). Studies have shown that docking alone cannot deliver authentic results. Hence, results obtained from MMPBSA are more authentic than the energy contributions obtained from the docking calculations only.

\subsection{Protein-Ligand Interaction Analysis}

Per-residue energy decomposition calculation was carried out to gain insight on each amino acid residue contribution towards the binding [24], the results are as shown in Figures 3 and 4. All the drugs bound in the N-terminal and C-terminal domain interface, an ATP binding site (Table S1, Supplementary Materials). Figure 3 displayed more hydrophobic interactions in the case of FadD32-Sorafenib (15) while FadD32-Mefloquine displayed the least hydrophobic interactions (6), and more hydrogen bonds were observed in the case of FadD32-Mefloquine (4) while FadD32-Sorafenib displayed the least hydrogen bonding (1). Hence, we can state that the total binding energy is influenced by the amount of energy contributed by each amino acid in the ligand binding not the number of amino acids bound to the ligand.

As shown in Figure 4, our results suggest that the highest residual energy contributions came from the following amino acids: Ile193 $(-2.84 \mathrm{kcal} / \mathrm{mol})$, Pro194 $(-2.38 \mathrm{kcal} / \mathrm{mol})$, and Phe625 $(-2.09 \mathrm{kcal} / \mathrm{mol})$ in the case of FadD32-Accolate, Tyr343 $(-2.63 \mathrm{kcal} / \mathrm{mol})$ and Arg192 (-1.73 kcal/mol) in case of FadD32-Sorafenib, Arg192 $(-2.41 \mathrm{kcal} / \mathrm{mol})$ in case of FadD32-Mefloquine, and Arg192 (-1.63 kcal/mol) in case of FadD32-Loperamide. Upon general observation, the van der Waals interactions showed significant contributions, towards the total binding energy, as compared to the electrostatic interactions (Figure 4). The best amino acid energy contributors form hydrogen bonds with the ligands, except in the case of FadD32-Sorafenib and the Phe625 in the case of FadD32-Accolate (Figure 3). These are further supported by the hydrogen bonding data presented in Table S2, Supplementary Materials. 

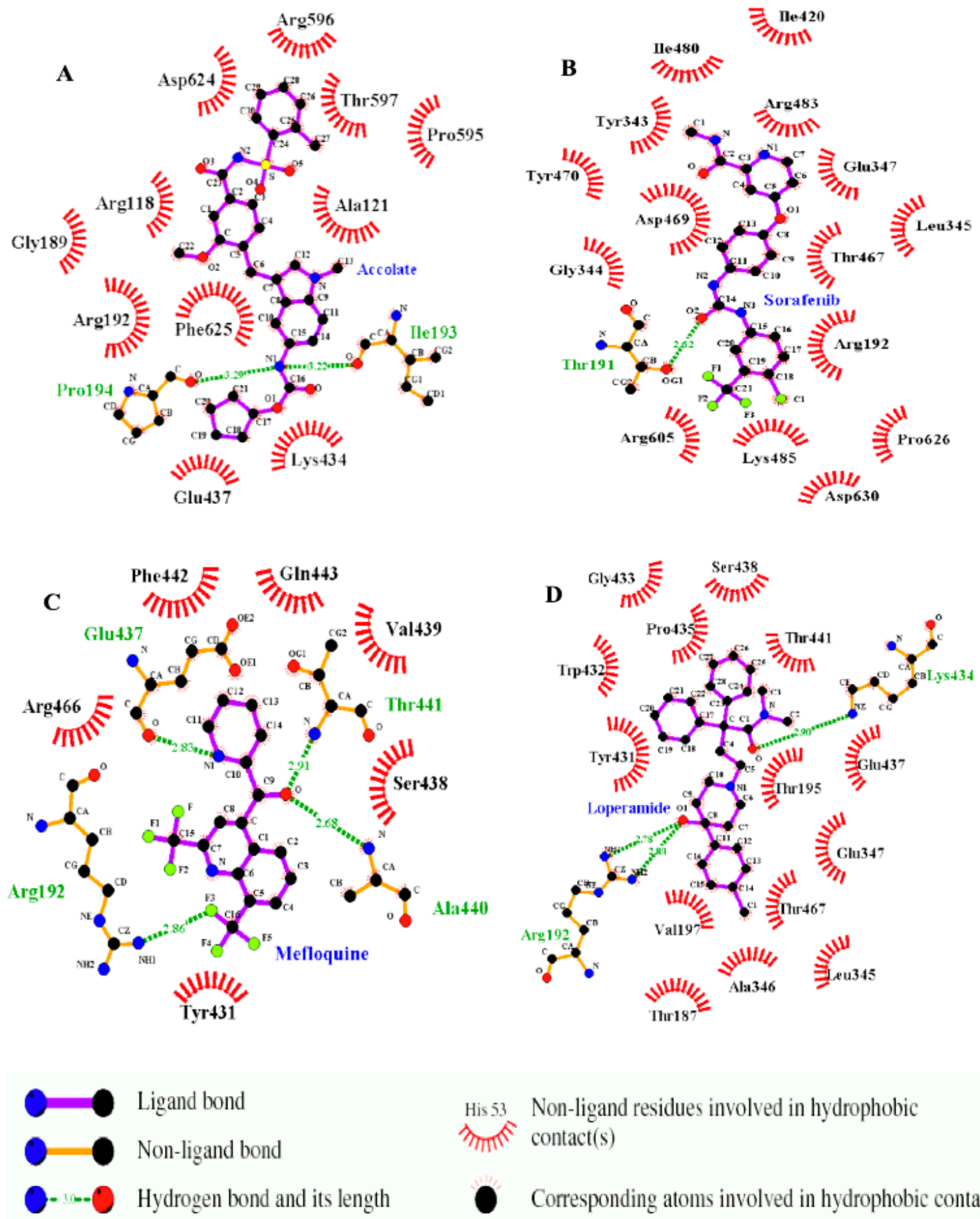

Ligand bond

Non-ligand bond

His 53 Non-ligand residues involved in hydrophobic

inलs $\operatorname{contact}(\mathrm{s})$

Hydrogen bond and its length

Corresponding atoms involved in hydrophobic contact|

Figure 3. Interaction profile of FadD32-Accolate (A), FadD32-Sorafenib (B), FadD32-Mefloquine (C), and FadD32-Loperamide (D). 

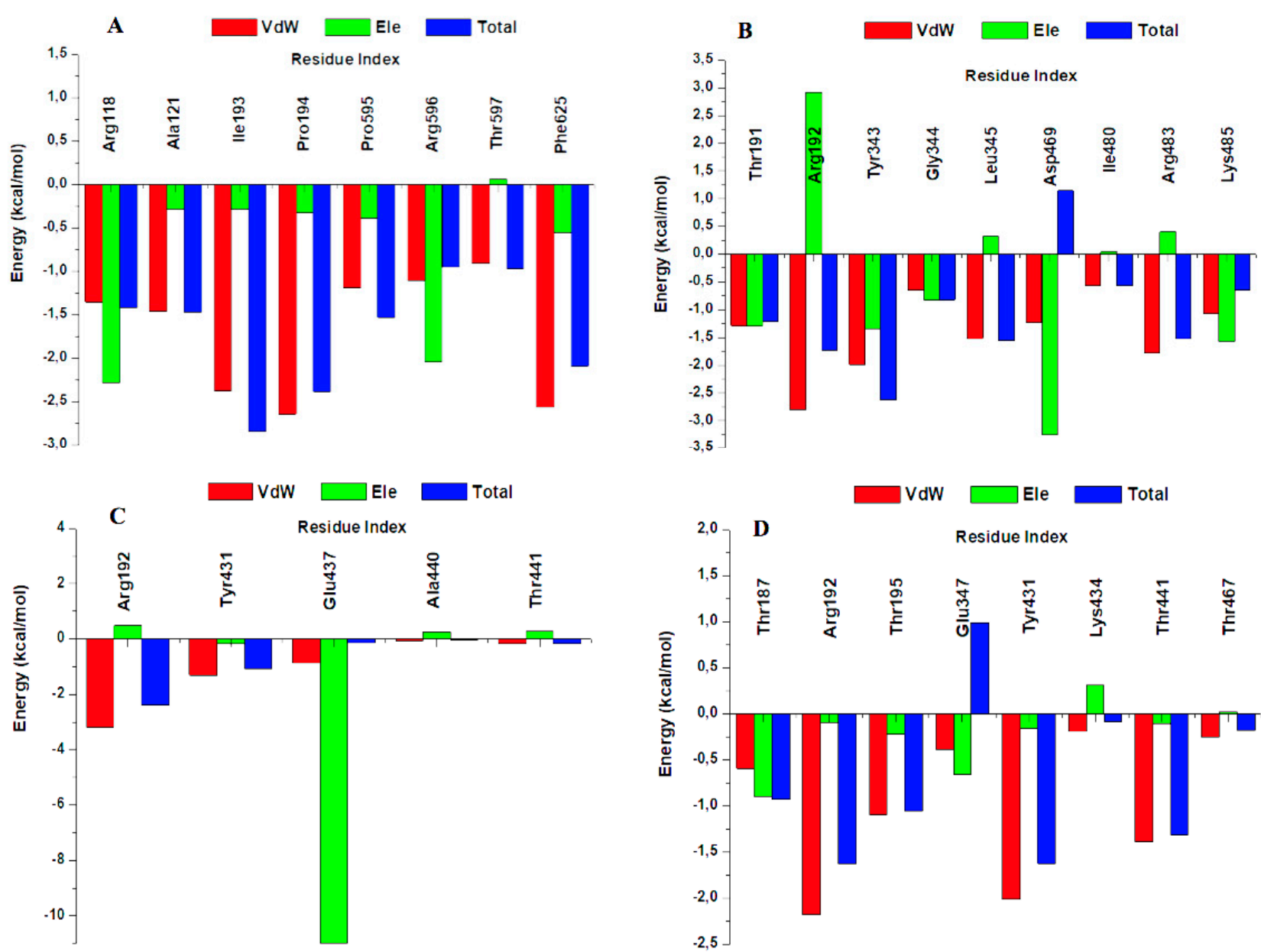

Figure 4. Per-residue decomposition analysis of FadD32-Accolate (A), FadD32-Sorafenib (B), FadD32Mefloquine, (C) and FadD32-Loperamide (D).

The results herein showed that the hit accolate drug formed more interactions with FadD32 active site residues as compared to the mefloquine, sorafenib, and loperamide. In addition, in the case of accolate, all active site residues displayed an increase in total binding contribution. We believe that the presence of a sulphur atom, in the case of accolate which is absent in other hits, leads to higher binding affinities. Hence, current drugs such as thioacetazone, isoxyl, and ethionamide for the treatment of TB targeting the mycolic acid biosynthetic pathway possess sulphur atoms [25]. In this work, we present novel potential inhibitors of the $M t b$-FadD32 bacteria as an alternative treatment for TB. Hence, our MMPBSA results strongly select the accolate hit as the most promising drug candidate for targeting $M t b$-FadD32.

\subsection{Structural Analysis}

The root mean square deviation (RMSD) describes the structure's conformational changes, by estimating the deviation in the $\mathrm{C} \alpha$ atoms of the residues on the backbone structure [26]. These conformational changes express the degree of protein stability. RMSD was calculated and the results are presented in Figure 5. 

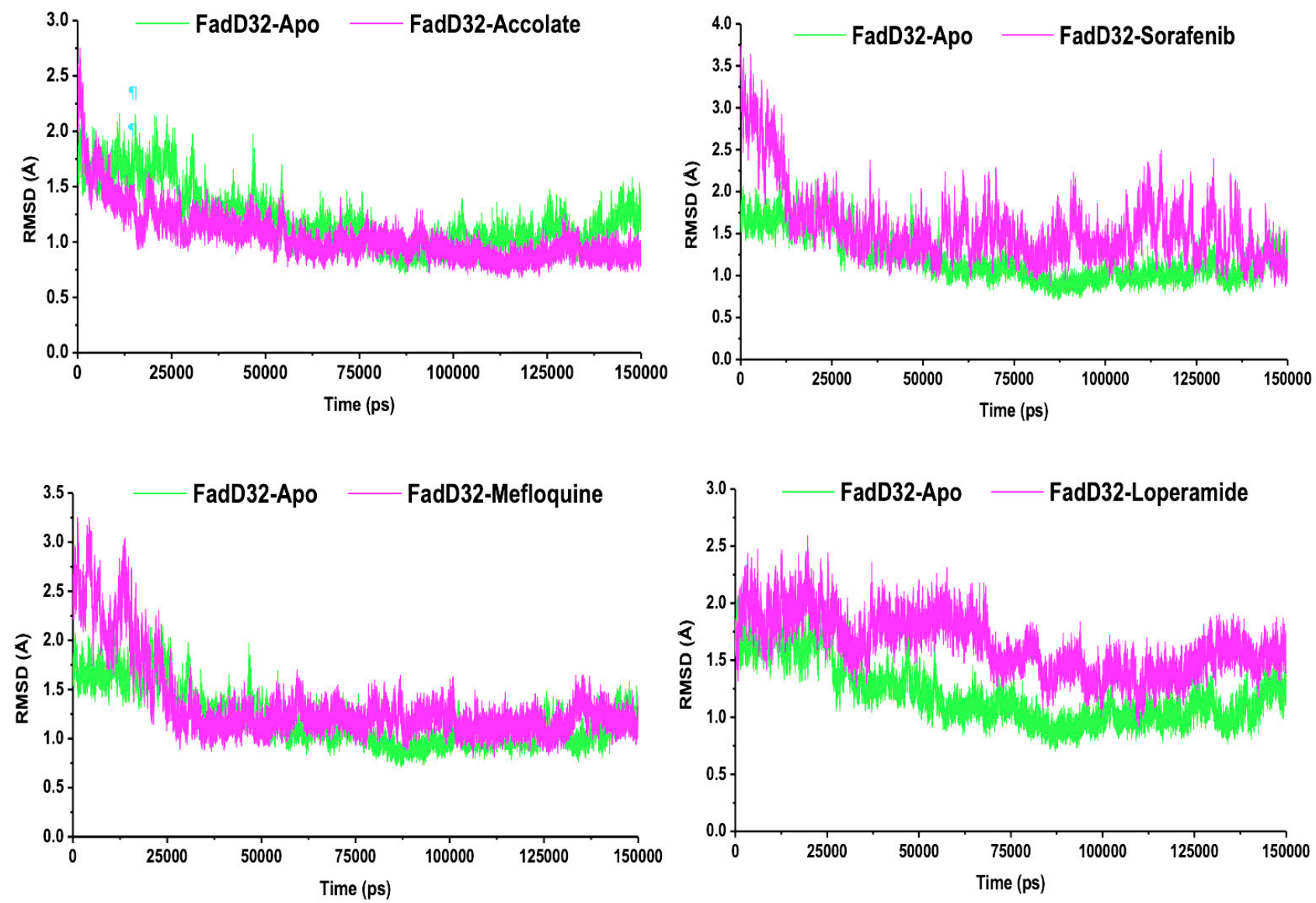

Figure 5. RMSD Plot of FadD32-Apo, FadD32-Accolate, FadD32-Sorafenib, FadD32-Mefloquine, and FadD32-Loperamide.

As shown in Figure 5, the RMSD of all systems were observed in the case of FadD32Accolate, FadD32-Apo, FadD32-Mefloquine, FadD32-Sorafenib, and FadD32-Loperamide with an average of $1.05 \AA, 1.20 \AA, 1.35 \AA, 1.56 \AA$, and $1.63 \AA$, respectively. The average RMSD values of all systems ranged from 1.05 to $1.63 \AA$. Hence, all systems were found to be stable with the average RMSD lower than the ideal of $3.0 \AA$ RMSD value [27].

\subsection{Influence of the Drugs on FadD32 Amino Acids Mobility}

The RMSF describes the dynamic behavior of individual amino acids within the structure, by estimating the $\mathrm{C} \alpha$ atoms fluctuations throughout the simulation [28]. These residue fluctuations express the degree of protein flexibility. To measure the degree of protein flexibility, RMSF was calculated, and the results are presented in Figure 6 with the average RMSF values ranging from 0.95 to $1.54 \AA$.

In Figure 6, the RMSF results show a similar trend as the RMSD where FadD32Accolate demonstrates low RMSF with an average of $0.95 \AA$ as compared to FadD32-Apo

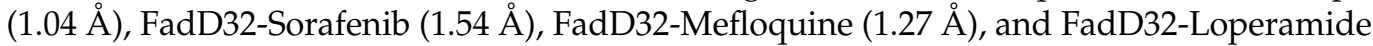
(1.32 $\AA$ ). Hence, our results suggest that the presence of accolate in the binding site reduced the mobility of amino acids as compared with sorafenib, mefloquine, and loperamide. In addition, in the case of the apo system, the most notable changes can be seen in the following regions: Arg269-Gly275 and Ile538-Asp543 showing higher fluctuation. However, the presence of accolate reduced the fluctuation in these regions. 

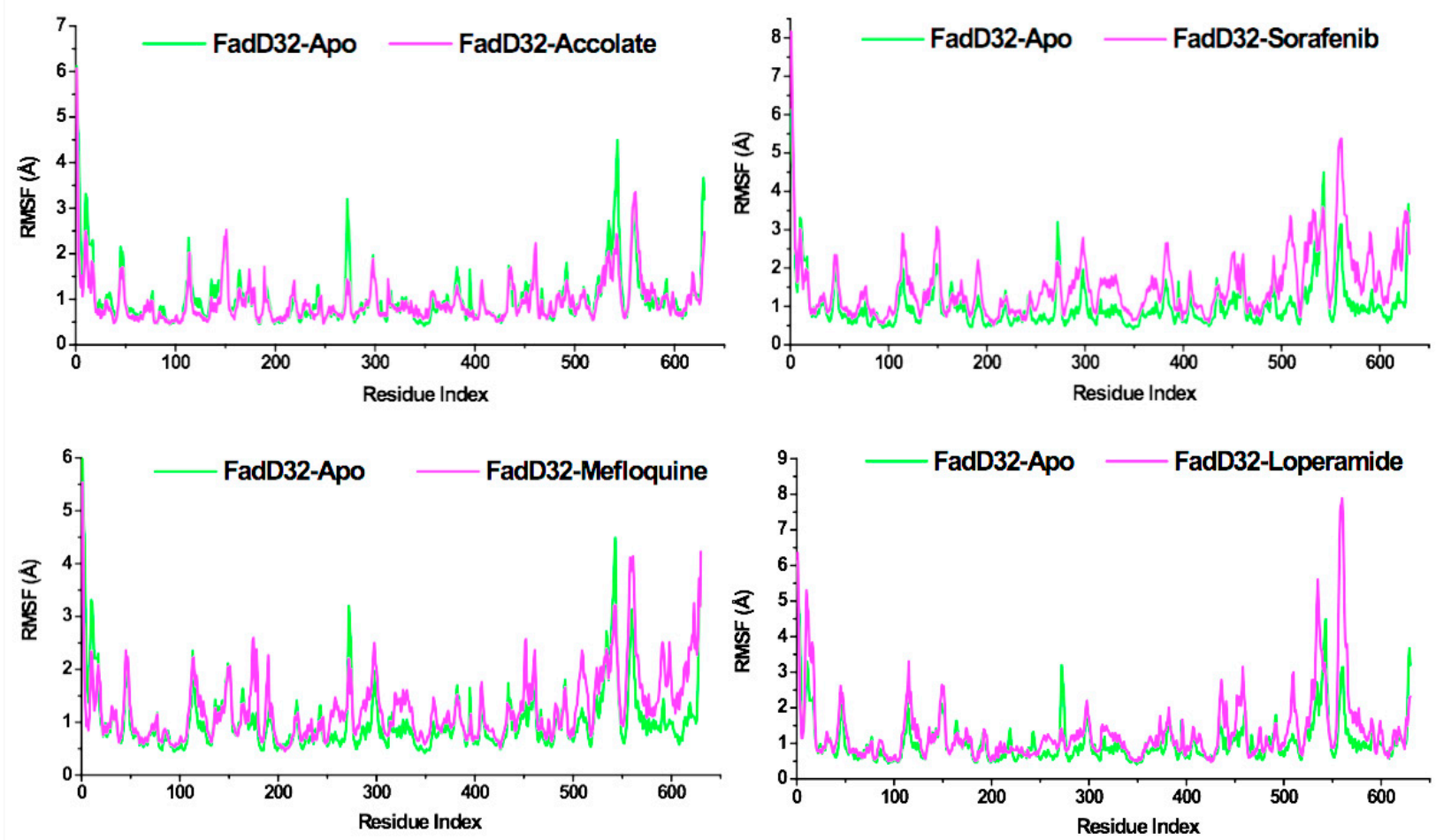

Figure 6. RMSF Plot of FadD32-Apo, FadD32-Accolate, FadD32-Sorafenib, FadD32-Mefloquine, and FadD32-Loperamide.

Our results conclude that the FadD32 protein is highly flexible during the process of biosynthesis of mycolic acids, essential for the growth and multiplication of the $M t b$. However, the presence of accolate in the binding site leads to conformational rigidity. These findings are in correlation with the RMSD results that suggest lower system stability (RMSD: $1.05 \AA$ ) in the case of FadD32-Accolate.

\subsection{Radius of Gyration ( $R g$ )}

In recent years, the radius of gyration has been applied to give insight into the level of compactness of the protein structure throughout the simulation [29]. To measure the level of compactness of the protein structure, $\mathrm{Rg}$ was calculated, and the results are presented in Figure 7 with the average $\mathrm{Rg}$ values ranging from $24.63-25.73 \AA$.

Figure 7 showed that, throughout the simulation, the FadD32-Accolate system displayed a lower Rg with an average of $24.63 \AA$, whereas FadD32-Apo (24.94 $\AA$ ), FadD32Sorafenib (25.73 $\AA$ ), FadD32-Mefloquine (24.87 $\AA$ ), and FadD32-Loperamide (24.91 $\AA$ ) displayed a higher Rg. These results suggest that the presence of accolate into the FadD32 protein exerts conformational stability and compactness within the protein as compared to the rest of the ligands. The calculated Rg results correlate with the estimated RMSD and RMSF, which justified increased biomolecular flexibility of FadD32 protein in the absence of accolate. Our results show that the FadD32 protein appeared to be highly affected by the presence of accolate. 

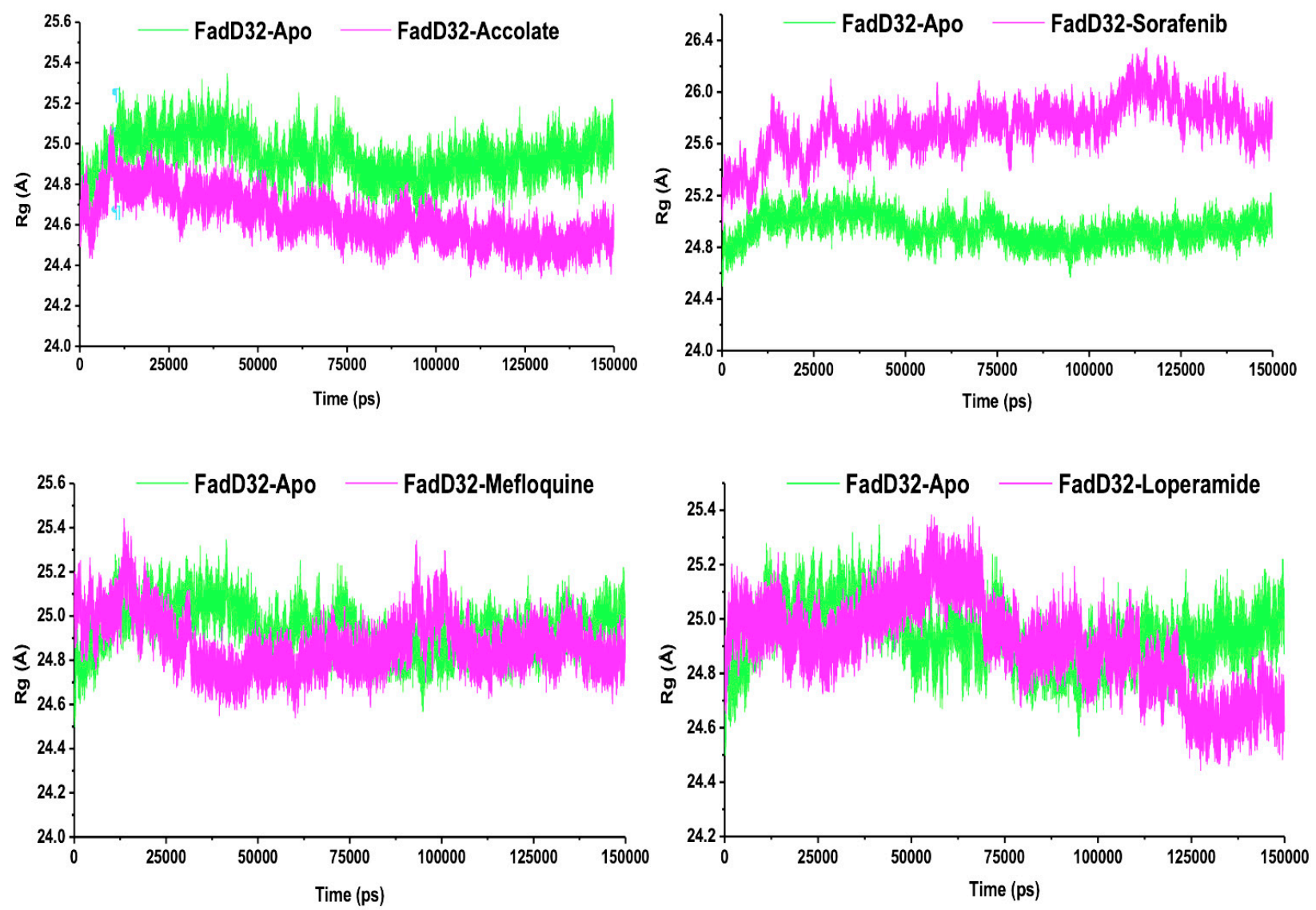

Figure 7. Radius of gyration plot of the FadD32-Apo, FadD32-Accolate, FadD32-Sorafenib, FadD32Mefloquine, and FadD32-Loperamide.

\subsection{Dynamic Cross-Correlation Matrices (DCCM)}

$\mathrm{DCCM}$ is a $3 \mathrm{D}$ matrix representation that gives insight on time-correlated residue motions of protein of interest [30]. DCCM analysis was conducted, and results are presented in Figure 8. The red-orange regions (0.5-1.0) represent strongly correlated/positive motions, whereas the yellow regions (0.25-0.50) represent slightly correlated motion, the green regions $(0.25$ to -0.25$)$ represent regions with no correlation motions (no movement) and the blue-light blue regions $(-0.50$ to -1.0$)$ represent strongly anti-correlated/negative motions.

Figure 8 displayed a positive correlation trend and a negative correlation trend at 1-250 and 500-630 residues, respectively, for all systems. Upon observation, the binding of all drugs introduced different dynamic changes within the FadD32 protein. The region of 1-250 relative to 1-250 residues in the case of FadD32-Accolate and FadD32-Sorafenib displayed the most strongly correlated motions, these are increased correlated motions when compared to FadD32-Apo. FadD32-Mefloquine demonstrated slightly correlated motions in this region. The region 480-630 relative to 1-250 residues, in the case of FadD32Accolate, has strongly anticorrelated motions as compared to the other systems. This can be due to numerous ligand interactions that occur in this region. Hence, there is reduced flexibility, and this aligns with the RMSF results (Figure 7). In the same region, FadD32-Sorafenib and FadD32-Loperamide matrices demonstrated anticorrelated motions and FadD32-Mefloquine displayed partially anticorrelated motions with patches of no correlation motions. The internal region, opposite the latter region, displayed anticorrelated motions with variant intensities for each system. These findings have shed light on the investigated drugs and the FadD32 protein. 

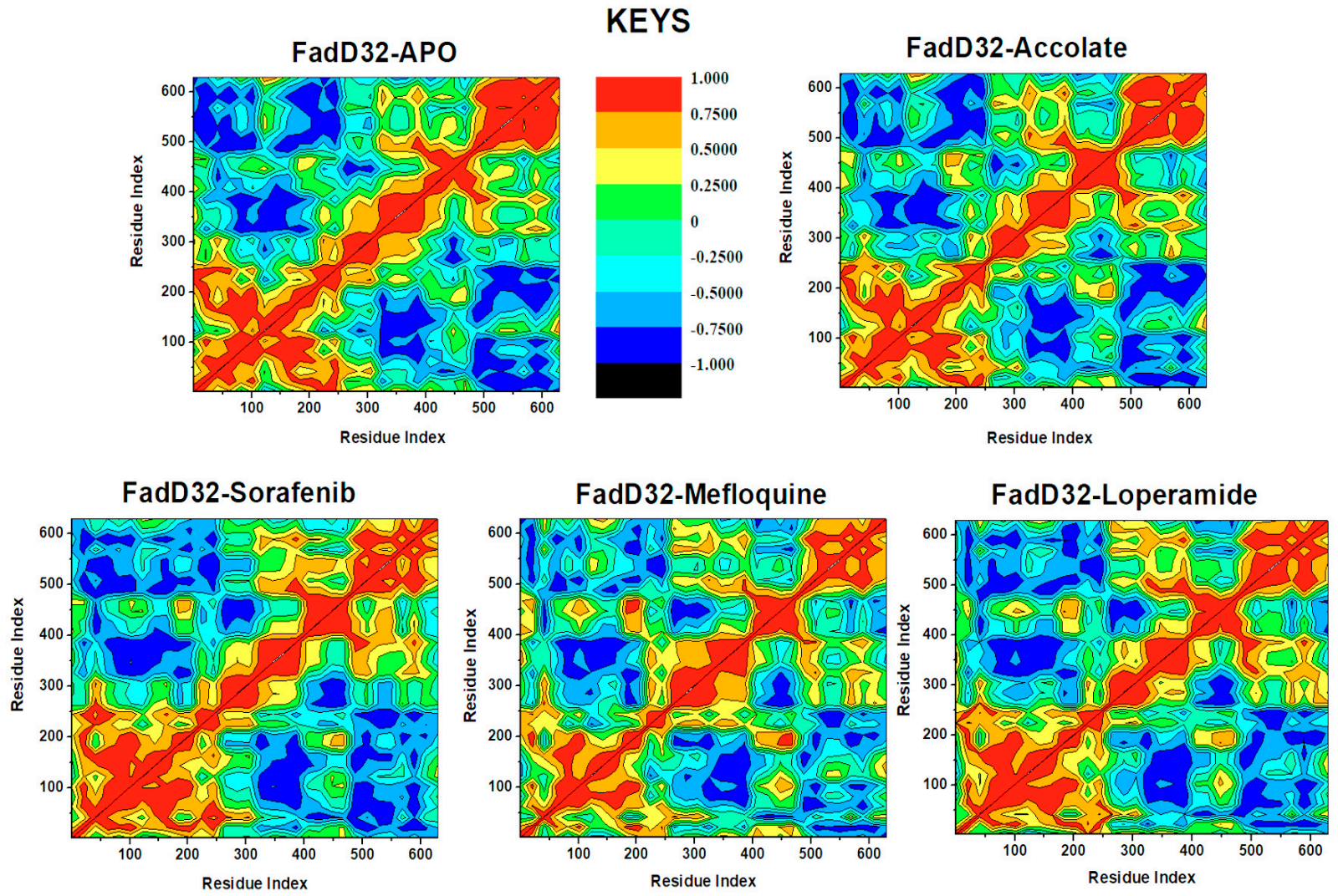

Figure 8. DCCM analysis graphs of the FadD32-Apo, FadD32-Accolate, FadD32-Sorafenib, FadD32Mefloquine, and FadD32-Loperamide.

\subsection{Principal Component Anaylisis (PCA)}

PCA is a technique used to understand complex motions and flexibility within a protein, in the presence and absence of a ligand or inhibitor [31]. The conformational changes are measured by the directional eigenvalues, PC1 vs. PC2. The MD trajectories of all the systems were subjected to PCA calculations, taking to account the C $\alpha$ atoms of residues and the results are depicted in Figure 9.

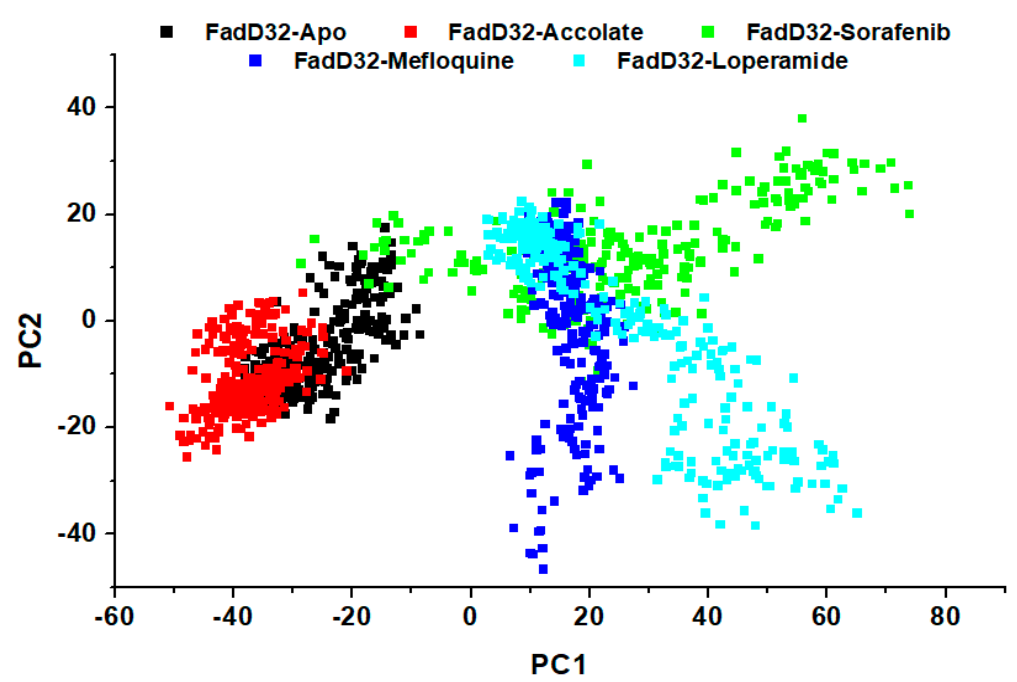

Figure 9. PCA analysis graph projecting the eigenvalues of FadD32-Apo, FadD32-Accolate, FadD32Sorafenib, FadD32-Mefloquine, and FadD32-Loperamide along PC1 and PC2. 
From the scatter plot in Figure 9, all the systems demonstrate different protein motions, the phase space occupied differs in the case of each system. FadD32-Accolate shows a pattern sort of similar to the FadD32-Apo, while occupying a smaller phase space and more compact. This proves that FadD32-Accolate exhibits lower molecular fluctuations as compared to the other systems, hence these results are consistent with the RMSD, RMSF, and $\mathrm{Rg}$ findings which stated that the binding of accolate reduced mobility on FadD32 residues and confers stability with the protein.

\subsection{In Silico ADME Predictions}

ADME predictions predict the nature, behavior, and fate of pharmaceutical drugs in an organism's body. These molecular physicochemical parameters are essential in drug design and drug approval. The drugs (accolate, sorafenib, loperamide, and mefloquine) were evaluated on SwissADME [32] web server based on Lipinski's rule of five and the results are presented in Tables 2 and 3. Lipinski's rule states that an orally active drug has no more than one violation of the following rules; molecular weight $\leq 500 \mathrm{~g} / \mathrm{mol}$, number of hydrogen atom donors $\leq 5$, number of hydrogen atom acceptors $\leq 10$, and the lipophilicity, $\log p \leq 4.15$ [33]. All the drugs satisfied Lipinski's rules (Table 2); hence, they have accepted drug absorption and permeation. This is further supported by the high bioavailability scores.

Table 2. Physicochemical parameters for the drugs.

\begin{tabular}{|c|c|c|c|c|}
\hline Parameters & Accolate & Sorafenib & Mefloquine & Loperamide \\
\hline Bioavailability score & 0.55 & 0.55 & 0.55 & 0.55 \\
\hline Molecular weight (g/mol) & 575.68 & 464.82 & 378.31 & 477.04 \\
\hline Hydrogen bond donors & 2 & 3 & 2 & 1 \\
\hline hydrogen bond acceptors & 7 & 7 & 9 & 3 \\
\hline Lipophilicity (MLOGP) & 3.92 & 2.91 & 3.43 & 4.17 \\
\hline Polarity: TPSA $\left(\AA^{2}\right)$ & 127.60 & 92.35 & 45.15 & 43.78 \\
\hline Lipinski violations & $1 ; \mathrm{Mw}>500$ & 0 & 0 & $1 ;$ MLOGP > 4.15 \\
\hline
\end{tabular}

Table 3. Pharmacokinetics parameters for the drugs.

\begin{tabular}{ccccc}
\hline Parameters & Accolate & Sorafenib & Mefloquine & Loperamide \\
\hline Gastrointestinal absorption & Low & Low & High & High \\
BBB permeant & No & No & No & Yes \\
P-glycoprotein substrate & No & No & No & Yes \\
CYP1A2 inhibitor & No & Yes & No & No \\
CYP2C19 inhibitor & No & Yes & No & No \\
CYP2C9 inhibitor & Yes & Yes & Yes & Yes \\
CYP2D2 inhibitor & No & Yes & -6.04 & Yes \\
CYP3A4 inhibitor & No & -6.25 & & -5.65 \\
$\log k_{\mathrm{p}}$ (skin permeant) $(\mathrm{cm} / \mathrm{s})$ & -5.52 & &
\end{tabular}

The results, described in Table 3, revealed that accolate and sorafenib had low human gastrointestinal absorption (HIA) and were not the substrate of P-glycoprotein (P-gp) while Mefloquine and Loperamide were found to be P-gp substrates and had high HIA. All the drugs have no blood-brain barrier (BBB) permeability except loperamide. Drug metabolism via CYP enzymes demonstrated variant results. All the drugs demonstrated positive ADME properties which suggest great promise for future treatment of TB. In addition, the usage and adverse effects of all selected FDA-approved drugs are given in Table 4. 
Table 4. Usage and adverse effects of identified MtbFadD32 potential inhibitors.

\begin{tabular}{|c|c|c|}
\hline Drugs & Usage & Adverse Effects \\
\hline Accolate & $\begin{array}{l}\text { Treats and manage asthma in children } \\
\qquad(\geq 5 \text { years old }) \text { and adults [34] }\end{array}$ & $\begin{array}{l}\text { Agitation, repetitive behaviours and } \\
\text { progressive liver failure [35] }\end{array}$ \\
\hline Sorafenib & $\begin{array}{l}\text { Treats unresectable liver carcinoma } \\
\text { and primary kidney cancer [36] }\end{array}$ & Diarrhea, fatigue and hypertension [37] \\
\hline Mefloquine & Treats malaria infections [38] & $\begin{array}{l}\text { Psychosis, convulsions and acute } \\
\text { brain syndrome [39] }\end{array}$ \\
\hline Loperamide & $\begin{array}{c}\text { Treats and control nonspecific and } \\
\text { chronic diarrhea [40] }\end{array}$ & $\begin{array}{l}\text { constipation, drowsiness and } \\
\text { abdominal discomfort [41] }\end{array}$ \\
\hline
\end{tabular}

\section{Methodology}

\subsection{Computational Procedure}

The X-ray crystal structure of MtbFadD32 (PDB:ID 5HM3) presented in the literature bears major discrepancies [11]. Hence, Mycobacterium smegmatis FadD32 structure was applied as a surrogate to evaluate drug leads against MtbFadD32. M. smegmatis $(M s m)$ is the frequently used model for $M t b$ as it is a good device for studying the properties of mycobacteria [42]. In addition, MsmFadD32 shares $74 \%$ sequence similarity with MtbFadD32 (Figure 10) [43], and most importantly Msm and Mtb show similar TB drug susceptibility [44].

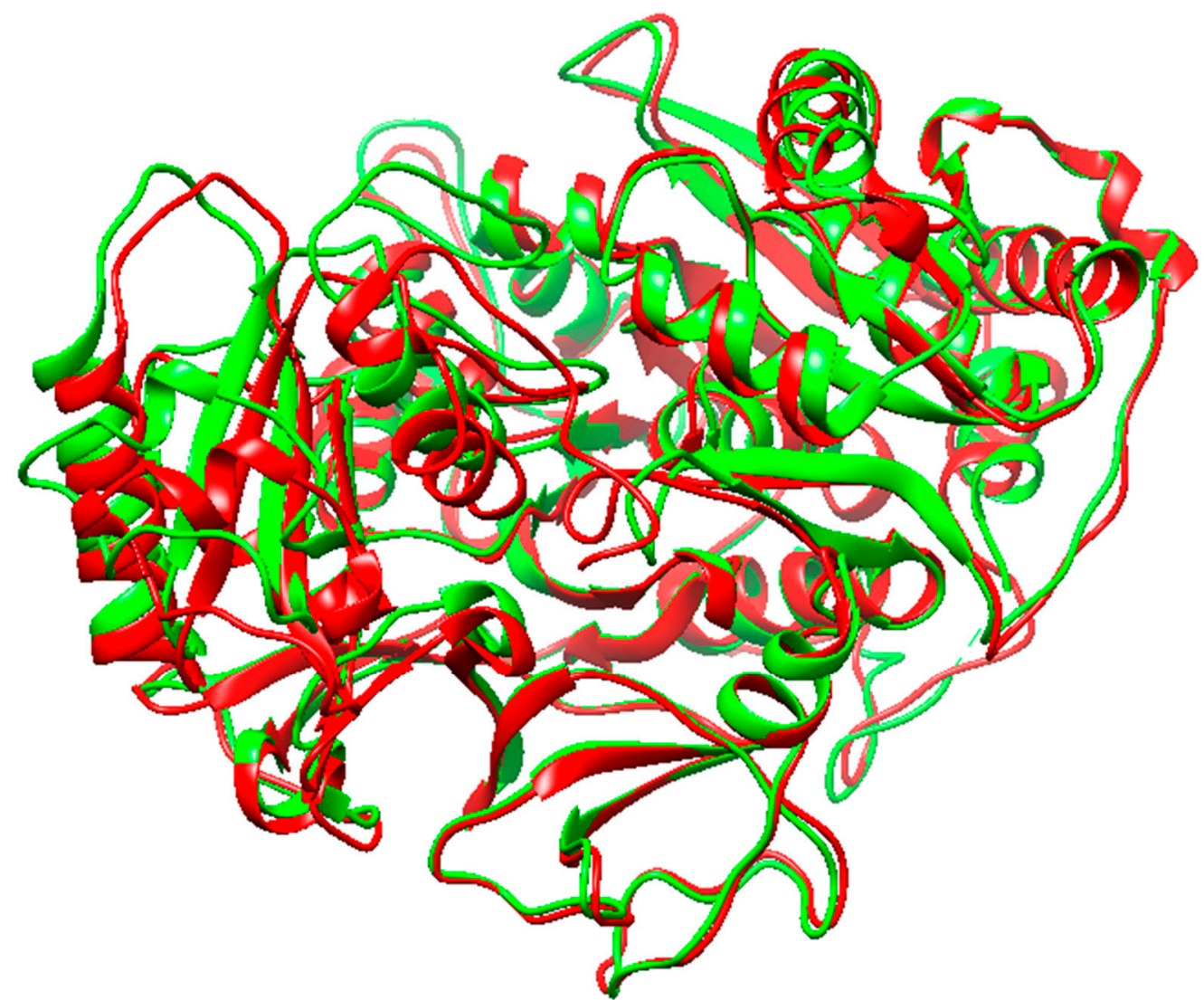

Figure 10. Aligned structures of $M t b F a d D 32$ (green) and MsmFadD32 (red) proteins.

\subsection{System Preparation}

In preparation for the molecular docking, Protein Data Bank (PDB) was used to obtain the X-ray structure of MsmFadD32 protein (PDB ID: 5D6J) [24]. The small molecules were retrieved from the ZINC database [45]. The UCSF Chimera [46] and Avogadro software [47] were used for the structural preparation of the MsmFadD32 receptor and the ligands. 


\subsection{Molecular Docking}

The molecular docking tool, AutoDock Vina [48] was used to carry out the docking calculations. The docking process was executed using the default AutoDock Vina parameters. Blind docking was performed, the gridbox housed the entire protein receptor and these grid parameters were generated $x=88, y=88$ and $z=104$ dimensions, $x=-34.57$, $\mathrm{y}=4.91$ and $\mathrm{z}=11.35$ centers with the exhaustiveness $=8$. The docked conformations of the receptor-ligand complex were generated in a Lamarckian genetic algorithm approach in the order of their docking scores [48]. Docked complex conformations with the best docking score were visualized with UCSF Chimera [46], then considered for molecular dynamic simulations.

\subsection{Molecular Dynamics (MD) Simulations}

The MD simulations of the systems were carried out using the GPU version of the PMEMD module implemented in the Amber 14 software, with the Amber force field FF14SB [49] and general Amber force field (GAFF) [50]. Antechamber module was utilized to generate atom's partial charges for ligands, hydrogen addition to protein, and system neutralization using the Leap module by adding the counter ions. The system was enclosed in a TIP3P water box, with a $10 \AA$ distance between the system surface and box boundary. The system was subjected to initial minimization for 2500 steps and then heated gradually from 0 to $300 \mathrm{~K}$ with $1 \mathrm{ps}, 5 \mathrm{kcal} \mathrm{mol}^{-1} \AA^{-2}$ (collision frequency and harmonic restraints, respectively) settings using Langevin thermostat [51]. The system was equilibrated with no restrictions at $300 \mathrm{~K}, 1$ bar constant pressure, and the SHAKE algorithm [52] restricted the system's bonds with hydrogen atoms. The system was subjected to a $150 \mathrm{~ns}$ MD in an isothermal-isobaric ensemble using Berendsen barostat, with 1 bar pressure and pressure-coupling constant of $2 \mathrm{ps}$. All other systems followed the same procedure.

\subsection{Post-MD Simulation Analysis}

After completing the $150 \mathrm{~ns}$ simulations, the MD trajectories were subjected to postanalysis calculations using the Amber14 modules PTRAJ and CPPTRAJ. These assist in the following analysis, MM-PBSA (molecular mechanics Poisson-Boltzmann surface area), Per-residue free energy decomposition analysis, hydrogen bonding analysis, RMSD (root mean square deviation), RMSF (root mean square fluctuation), $\mathrm{Rg}$ (radius of gyration) and DCCM (dynamic cross-correlation matrices).

The Equations (1) and (2) below describes how RMSD and RMSF are assessed:

$$
\operatorname{RMSD}=\left(\frac{\sum_{\mathrm{N}}\left(\mathrm{R}_{\mathrm{i}}-\mathrm{R}_{\mathrm{i}}^{0}\right)^{2}}{\mathrm{~N}}\right)^{\frac{1}{2}}
$$

where $\mathrm{N}$ is the number of $\mathrm{C} \alpha$ atoms in a complex, $\mathrm{R}_{\mathrm{i}}$ is the position of vector of the $\mathrm{C} \alpha$ atom $\mathrm{i}$, and $\mathrm{R}_{\mathrm{i}}^{0}$ is the position of vector for reference atom.

$$
\mathrm{sRMSF}_{\mathrm{i}}=\frac{\mathrm{RMSF}_{\mathrm{i}}-\mathrm{RMSF}}{\sigma(\mathrm{RMSF})}
$$

where sRMSFi is the standardized RMSF, RMSFi is RMSF of the ith residue, RMSF average RMSF, and $\sigma$ (RMSF) is the RMSF's standard deviation.

\subsection{Binding Free Energy Calculations and Per-Residue Free Energy Decomposition Analysis}

Binding free energy calculation is a thermodynamics method that offers insight into the protein-ligand interaction [53]. In this study, the calculations were computed using the MMPBSA approach, which is a popular method in drug design and estimates the interaction energy of protein-ligand (small molecules/inhibitor) complex [54]. All the system's output 
trajectories were subjected to the calculation and the following Equations (3)-(6) describe the calculations:

$$
\begin{gathered}
\Delta \mathrm{G}_{\text {binding }}=\mathrm{G}_{\text {complex }}-\left[\mathrm{G}_{\text {protein }}+\mathrm{G}_{\text {ligand }}\right] \\
\Delta \mathrm{G}_{\text {binding }}=\mathrm{E}_{\mathrm{MM}}+\mathrm{G}_{\text {sol }}-\mathrm{T} \Delta \mathrm{S} \\
\Delta \mathrm{E}_{\mathrm{MM}}=\mathrm{E}_{\text {ele }}+\mathrm{E}_{\mathrm{vdw}} \\
\mathrm{G}_{\text {sol }}=\mathrm{G}_{\text {polar }}+\mathrm{G}_{\text {non-polar }}
\end{gathered}
$$

where $\Delta G_{\text {binding }}$ denotes the protein-ligand complex's free energy, $E_{M M}$ is the sum of gas-phase molecular mechanics energy, $\mathrm{G}_{\text {sol }}$ denotes solvation free energy, and $\mathrm{T} \Delta \mathrm{S}$ is total entropy. $\Delta \mathrm{E}_{\mathrm{MM}}$ is the sum of electrostatic and van der Waals contributions which are denoted by $E_{\text {ele }}$ and $E_{v d w}$, respectively. $G_{\text {sol }}$ is the sum of polar and non-polar contributions,

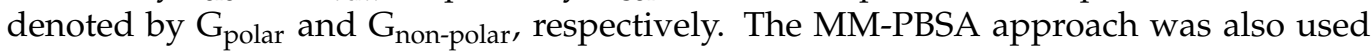
to determine the individual amino acid residue energy contributions towards the overall binding free energy. Protein-ligand interactions were visualized using LigPlot [55].

\subsection{Dynamic Cross-Correlation Matrices (DCCM)}

DCC between atoms is defined by the following expression:

$$
\mathrm{C}_{\mathrm{ij}}=\left\langle\Delta \mathrm{r}_{\mathrm{i}} \cdot \Delta \mathrm{r}_{\mathrm{j}}\right\rangle /\left(\left\langle\Delta \mathrm{r}_{\mathrm{i}}{ }^{2}\right\rangle\left\langle\Delta \mathrm{r}_{\mathrm{j}}{ }^{2}\right\rangle\right)^{1 / 2}
$$

In Equation (7), ith and $j$ th denote the amino acids with their spatial backbone atom positions $r_{i}$ and $r_{j} . \Delta r_{i}$ indicates the $i$ th displacement from its mean position over time [56]. Each Cij element has a time scale associated with it, that correlates with a dataset of adjoining snapshot structures taken from the temporal succession of snapshot structures saved on the MD trajectory. The MD trajectories of different systems were subjected to the calculations and the matrices were generated, the Origin software [57] was used to analyze the atomic correlative motion results obtained.

\subsection{Principal Component Analysis (PCA)}

Principal components of the protein motion were calculated as described below:

$$
C_{i j}=\left\langle\left(x_{i}-\left\langle x_{j}\right\rangle\right)\right\rangle(i, j=1,2,3, \ldots, 3 N),
$$

where $\mathrm{N}$ is the number of $\mathrm{C} \alpha$ atoms, $\mathrm{x}_{\mathrm{i}}$ and $\mathrm{x}_{\mathrm{j}}$ are Cartesian coordinates of the $i$ th and $j$ th atoms respectively and $\left\langle\mathrm{x}_{\mathrm{i}}\right\rangle,\left\langle\mathrm{x}_{\mathrm{j}}\right\rangle$ denote the average time of all configurations of all the configurations obtained in MD simulation [58]. The MD trajectories of all the systems were subjected to the calculations and the Origin software [57] was used to draw the graphs for analysis.

\subsection{In Silico ADME Predictions}

The SwissADME web tool [32] was utilized for the assessment of absorption, distribution, metabolism, and excretion (ADME) parameters of the investigated drugs. This drug data is essential for drug approval, as it reveals the drug-likeness of the investigated drugs. The tool reveals the bioavailability of the drug candidates by estimating the following physicochemical properties: lipophilicity, size, polarity, solubility, saturation, and flexibility. The default predictors were used for this study.

\section{Conclusions}

Frequent development of drug resistance by $M t b$ against most approved TB drugs remains a major global threat, hence, motivates the urgent need for new effective drugs and new drug targets. In this report, we embarked on various computational approaches such as virtual screening (VS), molecular docking, and molecular dynamic (MD) simulation in order to identify potential FDA-approved drugs against fatty acid degradation protein D32 (FadD32), a novel drug target. The calculated ligand-protein binding energies ranged 
from -45.13 to $-21.52 \mathrm{kcal} / \mathrm{mol}$, with accolate $(-45.13 \mathrm{kcal} / \mathrm{mol})$ showing the highest total binding energy. It was observed that accolate also had the highest van der Waals and electrostatic contributions towards the total binding free energy $\left(\Delta \mathrm{E}_{\mathrm{vdw}}\right.$ of $-64.54 \mathrm{kcal} / \mathrm{mol}$ and $\Delta \mathrm{E}_{\text {ele }}$ of $-28.89 \mathrm{kcal} / \mathrm{mol}$ ). Hence, the current study identified accolate as the best potential drug inhibitor of FadD32. Per-residue energy decomposition calculations suggest that the highest residual energy contributions came from Ile193 $(-2.84 \mathrm{kcal} / \mathrm{mol})$, Pro194 $(-2.38 \mathrm{kcal} / \mathrm{mol})$, and Phe625 $(-2.09 \mathrm{kcal} / \mathrm{mol})$ in the case of FadD32-Accolate. Therefore, the molecular structure of these residues will require careful consideration when designing inhibitors targeting FadD32. To provide insight into the structural, and mechanistic features of accolate as an FadD32 inhibitor, structural analysis was carried out by computing RMSD, RMSF, Rg, DCC and PCA. Accolate binding leads to FadD32 structural stability, hence reduced residue mobility and increased compactness of protein structure. Our results strongly suggest accolate as a potential inhibitor of $M t b F a d D 32$, however, an experimental approach is required to validate the current hypothesis. We believe these findings will advance the design of potent $M t b$ inhibitors towards the treatment of TB.

Supplementary Materials: The following are available online. Table S1: Binding sites and the amino acids residues. Table S2: $\mathrm{H}$ bonding data of the investigated drugs. Table S3: Binding free energy $(\mathrm{kcal} / \mathrm{mol})$ and the components of binding free energy of the respective molecules. Figure S1: RMSD of FadD32-Apo, FadD32-Accolate, FadD32-Sorafenib, FadD32-Mefloquine and FadD32-Loperamide. Table S4: RMSD ( $)$ values and average.

Author Contributions: Conceptualization, N.N.M.; Methodology, N.T.P.N. and K.E.M.; Software, N.T.P.N. and K.E.M.; Validation, N.N.M. and K.E.M.; Formal analysis, N.T.P.N. and K.E.M.; Investigation, N.T.P.N. and K.E.M.; Resources, N.N.M.; Data curation, N.T.P.N. and K.E.M.; Writing—original draft preparation, N.T.P.N. and K.E.M.; Writing-review and editing, N.T.P.N. and K.E.M.; Visualization, N.T.P.N. and K.E.M.; Supervision, N.N.M.; Project administration, N.N.M.; Funding and acquisition, Not funded. All authors have read and agreed to the published version of the manuscript.

Funding: This research received no external funding.

Institutional Review Board Statement: Not applicable.

Informed Consent Statement: Not applicable.

Data Availability Statement: Data is contained within the article or Supplementary Materials.

Acknowledgments: The authors acknowledge the Centre for High Performance Computing (CHPC, www.chpc.ac.za), Cape Town, South Africa, for computational resources.

Conflicts of Interest: The authors declare no financial and intellectual conflict of interest.

Sample Availability: The identified compounds are presented as 2D structures in the manuscript in Figure 2, with their respective names. Should the reader be interested in these, they can fetch them directly from the ZINC database as mentioned in the methods section of the manuscript.

\section{References}

1. WHO. Global Tuberculosis Report; World Health Organization: Geneva, Switzerland, 2020. [CrossRef]

2. Dobler, C.C.; Martin, A.; Marks, G.B. Benefit of treatment of latent tuberculosis infection in individual patients. Eur. Respir. J. 2015, 46, 1397-1406. [CrossRef] [PubMed]

3. Seung, K.J.; Keshavjee, S.; Rich, M.L. Multidrug-resistant tuberculosis and extensively drug-resistant tuberculosis. Cold Spring Harb. Perspect. Med. 2015, 5, a017863. [CrossRef] [PubMed]

4. Alsayed, S.S.R.; Beh, C.C.; Foster, N.R.; Payne, A.D.; Yu, Y.; Gunosewoyo, H. Kinase targets for mycolic acid biosynthesis in Mycobacterium tuberculosis. Curr. Mol. Pharmacol. 2019, 12, 27-49. [CrossRef] [PubMed]

5. Zhang, W.; Lun, S.; Wang, S.H.; Jiang, X.W.; Yang, F.; Tang, J.; Manson, A.L.; Gunosewoyo, H.; Bishai, W.R.; Yu, L.-F. Identification of Novel Coumestan Derivatives as Polyketide Synthase 13 Inhibitors against Mycobacterium tuberculosis. J. Med. Chem. 2018, 61,791-803. [CrossRef]

6. $\quad$ Fang, C.; Lee, K.K.; Nietupski, R.; Bates, R.H.; Fernandez-Menendez, R.; Lopez-Roman, E.M.; Guijarro-Lopez, L.; Yin, Y.; Peng, Z.; Gomez, J.E.; et al. Discovery of heterocyclic replacements for the coumarin core of anti-tubercular FadD32 inhibitors. Bioorg. Med. Chem. Lett. 2018, 28, 3529-3533. [CrossRef] 
7. Batt, S.M.; Minnikin, D.E.; Besra, G.S. The thick waxy coat of mycobacteria, a protective layer against antibiotics and the host's immune system. Biochem. J. 2020, 447, 1983-2006. [CrossRef]

8. Kleandrova, V.V.; Scotti, M.T.; Speck-Planche, A. Computational drug repurposing for antituberculosis therapy: Discovery of multi-strain inhibitors. Antibiotics 2021, 10, 1005. [CrossRef]

9. Marrakchi, H.; Lanéelle, M.A.; Daffé, M. Mycolic acids: Structures, biosynthesis, and beyond. Chem. Biol. 2014, 21, 67-85. [CrossRef]

10. Li, W.; Gu, S.; Fleming, J.; Bi, L. Crystal structure of FadD32, an enzyme essential for mycolic acid biosynthesis in mycobacteria. Sci. Rep. 2015, 5, 15493. [CrossRef]

11. Kuhn, M.L.; Alexander, E.; Minasov, G.; Page, H.J.; Warwrzak, Z.; Shuvalova, L.; Flores, K.J.; Wilson, D.J.; Shi, S.; Aldrich, C.C.; et al. Structure of the Essential Mtb FadD32 Enzyme: A Promising Drug Target for Treating Tuberculosis. ACS Infect. Dis. 2016, 2, 579-591. [CrossRef]

12. Rudrapal, M.; Khairnar, S.J.; Jadhav, A.G. Drug Repurposing (DR): An Emerging Approach in Drug Discovery. Drug RepurposingHypothesis Mol. Asp. Ther. Appl. 2020. [CrossRef]

13. Diallo, B.N.; Swart, T.; Hoppe, H.C.; Tastan Bishop, Ö.; Lobb, K. Potential repurposing of four FDA approved compounds with antiplasmodial activity identified through proteome scale computational drug discovery and in vitro assay. Sci. Rep. 2021, 11, 1413. [CrossRef]

14. Maitra, A.; Bates, S.; Kolvekar, T.; Devarajan, P.V.; Guzman, J.D.; Bhakta, S. Repurposing-a ray of hope in tackling extensively drug resistance in tuberculosis. Int. J. Infect. Dis. 2015, 32, 50-55. [CrossRef]

15. An, Q.; Li, C.; Chen, Y.; Deng, Y.; Yang, T.; Luo, Y. Repurposed drug candidates for antituberculosis therapy. Eur. J. Med. Chem. 2020, 192, 112175. [CrossRef]

16. Sotgiu, G.; D'Ambrosio, L.; Centis, R.; Tiberi, S.; Esposito, S.; Dore, S.; Spanevello, A.; Battista Migliori, G. Carbapenems to treat multidrug and extensively drug-resistant tuberculosis: A systematic review. Int. J. Mol. Sci. 2016, 17, 373. [CrossRef]

17. Walters, W.P.; Wang, R. New trends in virtual screening. J. Chem. Inf. Modeling 2020, 60, 4109-4111. [CrossRef]

18. De Sousa, A.C.C.; Combrinck, J.M.; Maepa, K.; Egan, T.J. Virtual screening as a tool to discover new $\beta$-haematin inhibitors with activity against malaria parasites. Sci. Rep. 2020, 10, 3374. [CrossRef]

19. Gimeno, A.; Ojeda-Montes, M.J.; Tomás-Hernández, S.; Cereto-Massagué, A.; Beltrán-Debón, R.; Mulero, M.; Pujadas, G.; Garcia-Vallve, S. The light and dark sides of virtual screening: What is there to know? Int. J. Mol. Sci. 2019, 20, 1375. [CrossRef]

20. Maia, E.H.B.; Assis, L.C.; de Oliveira, T.A.; da Silva, A.M.; Taranto, A.G. Structure-Based Virtual Screening: From Classical to Artificial Intelligence. Front. Chem. 2020, 8, 343. [CrossRef]

21. Van Gunsteren, W.F.; Berendsen, H.J.C. A leap-frog algorithm for stochastic dynamics. Mol. Simul. 1988, 1, 173-185. [CrossRef]

22. Wang, Y.; Lamim Ribeiro, J.M.; Tiwary, P. Machine learning approaches for analyzing and enhancing molecular dynamics simulations. Curr. Opin. Struct. Biol. 2020, 61, 139-145. [CrossRef]

23. Fogolari, F.; Brigo, A.; Molinari, H. Protocol for MM/PBSA molecular dynamics simulations of proteins. Biophys. J. 2003, 85, 159-166. [CrossRef]

24. Chaudhary, N.; Aparoy, P. Application of per-residue energy decomposition to identify the set of amino acids critical for in silico prediction of COX-2 inhibitory activity. Heliyon 2020, 6, e04944. [CrossRef]

25. North, E.J.; Jackson, M.; Lee, R. New Approaches to Target the Mycolic Acid Biosynthesis Pathway for the Development of Tuberculosis Therapeutics. Curr. Pharm. Des. 2014, 20, 4357-4378. [CrossRef]

26. Dixit, S.B.; Ponomarev, S.Y.; Beveridge, D.L. Root mean square deviation probability analysis of molecular dynamics trajectories on DNA. J. Chem. Inf. Modeling 2006, 46, 1084-1093. [CrossRef]

27. Xiang, Z.; Soto, C.S.; Honig, B. Evaluating conformational free energies: The colony energy and its application to the problem of loop prediction. Proc. Natl. Acad. Sci. USA 2002, 99, 7432-74377. [CrossRef]

28. Sneha, P.; Priya Doss, C.G. Molecular Dynamics: New Frontier in Personalized Medicine. In Advances in Protein Chemistry and Structural Biology, 1st ed.; Elsevier Inc.: Amsterdam, The Netherlands, 2016; Volume 102. [CrossRef]

29. Buthelezi, N.M.; Mhlongo, N.N.; Amoako, D.G.; Somboro, A.M.; Sosibo, S.C.; Shunmugam, L.; Machaba, K.E.; Kumalo, H.M. Exploring the impact of $\mathrm{H} 5 \mathrm{~N} 1$ neuraminidase $(\mathrm{H} 274 \mathrm{Y})$ mutation on Peramivir: A bio-computational study from a molecular perspective. J. Biomol. Struct. Dyn. 2020, 38, 4344-4352. [CrossRef]

30. Qureshi, R.; Ghosh, A.; Yan, H. Correlated Motions and Dynamics in Different Domains of EGFR with L858R and T790M Mutations. IEEE/ACM Trans. Comput. Biol. Bioinform. 2020, 5963, 1. [CrossRef]

31. Halder, A.K.; Honarparvar, B. Molecular alteration in drug susceptibility against subtype B and C-SA HIV-1 proteases: MD study. Struct. Chem. 2019, 30, 1715-1727. [CrossRef]

32. Daina, A.; Michielin, O.; Zoete, V. SwissADME: A free web tool to evaluate pharmacokinetics, drug-likeness and medicinal chemistry friendliness of small molecules. Sci. Rep. 2017, 7, 42717. [CrossRef]

33. Gupta, N.; Choudhary, S.K.; Bhagat, N.; Karthikeyan, M.; Chaturvedi, A. In silico prediction, molecular docking and dynamics studies of steroidal alkaloids of holarrhena pubescens wall. ex G. don to guanylyl cyclase C: Implications in designing of novel antidiarrheal therapeutic strategies. Molecules 2021, 26, 4147. [CrossRef] [PubMed]

34. Scow, D.T.; Luttermoser, G.K.; Dickerson, K.S. Leukotriene inhibitors in the treatment of allergy and asthma. Am. Fam. Physician 2007, 75, 65-70. [PubMed]

35. White, D.J.; Vanthuyne, A.; Wood, P.M.; Ayres, J.G. Zafirlukast for severe recurrent vulvovaginal candidiasis: An open label pilot study. Sex. Transm. Infect. 2004, 80, 219-222. [CrossRef] [PubMed] 
36. Gauthier, A.; Ho, M. Role of sorafenib in the treatment of advanced hepatocellular carcinoma: An update. Hepatol. Res. 2013, 43, 147-154. [CrossRef]

37. Li, Y.; Gao, Z.H.; Qu, X.J. The adverse effects of sorafenib in patients with advanced cancers. Basic Clin. Pharmacol. Toxicol. 2015, 116, 216-221. [CrossRef]

38. Gobbi, F.; Rossanese, A.; Buonfrate, D.; Angheben, A.; Lunardi, G.; Bisoffi, Z. Failure of malaria chemoprophylaxis with mefloquine in an oversize traveller to Mozambique. Malar. J. 2013, 12, 451. [CrossRef]

39. Lee, S.J.; Ter Kuile, F.O.; Price, R.N.; Luxemburger, C.; Nosten, F. Adverse effects of Mefloquine for the treatment of uncomplicated malaria in Thailand: A pooled analysis of 19, 850 individual patients. PLoS ONE 2017, 12, e0168780. [CrossRef]

40. Regnard, C.; Twycross, R.; Mihalyo, M.; Wilcock, A. Loperamide. J. Pain Symptom Manag. 2011, 42, 319-323. [CrossRef]

41. Ali, Z.; Shoukat, U.; Khan, M.; Roomi, S.; Ullah, W. ‘Loperamide overdose induces ventricular tachycardia with catastrophic outcomes'. J. Community Hosp. Intern. Med. Perspect. 2020, 10, 229-232. [CrossRef]

42. Sundarsingh, J.A.; Ranjitha Rajan, A.; Shankar, V. Features of the biochemistry of Mycobacterium smegmatis, as a possible model for Mycobacterium tuberculosis. J. Infect. Public Health 2020, 13, 1255-1264. [CrossRef]

43. Guillet, V.; Galandrin, S.; Maveyraud, L.; Ladevèze, S.; Mariaule, V.; Bon, C.; Eynard, N.; Daffé, M.; Marrakchi, H.; Mourey, L. Insight into structure-function relationships and inhibition of the fatty Acyl-AMP ligase (FadD32) orthologs from mycobacteria. $J$. Biol. Chem. 2016, 291, 7973-7989. [CrossRef]

44. Lelovic, N.; Mitachi, K.; Yang, J.; Lemieux, M.R.; Ji, Y.; Kurosu, M. Application of Mycobacterium smegmatis as a surrogate to evaluate drug leads against Mycobacterium tuberculosis. J. Antibiot. 2020, 73, 780-789. [CrossRef]

45. Sterling, T.; Irwin, J.J. ZINC 15-Ligand Discovery for Everyone. J. Chem. Inf. Modeling 2015, 55, 2324-2337. [CrossRef]

46. Huang, C.C.; Meng, E.C.; Morris, J.H.; Pettersen, E.F.; Ferrin, T.E. Enhancing UCSF Chimera through web services. Nucleic Acids Res. 2014, 42, 478-484. [CrossRef]

47. Rayan, B.; Rayan, A. Avogadro Program for Chemistry Education: To What Extent can Molecular Visualization and Threedimensional Simulations Enhance Meaningful Chemistry Learning? World J. Chem. Educ. 2017, 5, 136-141. [CrossRef]

48. Allouche, A.R. Software News and Updates Gabedit-A Graphical User Interface for Computational Chemistry Softwares. J. Comput. Chem. 2012, 32, 174-182. [CrossRef]

49. Case, D.A.; Babin, V.; Berryman, J.T.; Betz, R.M.; Cai, Q.; Cerutti, D.S.; Cheatham, T.E., III; Darden, T.A.; Duke, R.E.; Gohlke, H.; et al. AMBER 14; University of California: San Francisco, CA, USA, 2014.

50. Wang, J.; Wolf, R.M.; Caldwell, J.W.; Kollman, P.A.; Case, D.A. Development and testing of a general amber force field. J. Comput. Chem. 2004, 56531, 1157-1174. [CrossRef]

51. Moustafa, S.G.; Schultz, A.J.; Kofke, D.A. Effects of thermostatting in molecular dynamics on anharmonic properties of crystals: Application to fcc Al at high pressure and temperature. J. Chem. Phys. 2018, 149, 124109. [CrossRef]

52. Ryckaert, J.P.; Ciccotti, G.; Berendsen, H.J.C. Numerical integration of the cartesian equations of motion of a system with constraints: Molecular dynamics of n-alkanes. J. Comput. Phys. 1977, 23, 327-341. [CrossRef]

53. Singh, N.; Li, W. Absolute binding free energy calculations for highly flexible protein MDM2 and its inhibitors. Int. J. Mol. Sci. 2020, 21, 4765. [CrossRef]

54. Genheden, S.; Ryde, U. The MM/PBSA and MM/GBSA methods to estimate ligand-binding affinities. Expert Opin. Drug Discov. 2015, 10, 449-461. [CrossRef]

55. Laskowski, R.; Swindells, M. LigPlot+: Multiple ligand-protein interaction diagrams for drug discovery. J. Chem. Inf. Model. 2011, 51, 2778-2786. [CrossRef]

56. Kasahara, K.; Fukuda, I.; Nakamura, H. A novel approach of dynamic cross correlation analysis on molecular dynamics simulations and its application to Ets1 dimer-DNA complex. PLoS ONE 2014, 9, e112419. [CrossRef]

57. Moberly, J.G.; Bernards, M.T.; Waynant, K.V. Key features and updates for origin 2018. J. Cheminformatics 2018, 10, 5. [CrossRef]

58. Machaba, K.E.; Cele, F.N.; Mhlongo, N.N.; Soliman, M.E.S. Sliding Clamp of DNA Polymerase III as a Drug Target for TB Therapy: Comprehensive Conformational and Binding Analysis from Molecular Dynamic Simulations. Cell Biochem. Biophys. 2016, 74, 473-481. [CrossRef] 